\title{
La organización de la justicia. Una mirada a través de la folletería mexicana del siglo xIX, 1821-1857
}

Laura Solares Robles

INSTITUTO MORA

\begin{abstract}
Se hace un balance del número, los temas y los periodos de publicación de los folletos dedicados a la organización de la justicia.
\end{abstract}

0 in duda, el siglo XIX, como fuente de conocimientos, seguirá presentándose ante los ojos de los historiadores interesados, como un manantial inagotable de sorpresas, descubrimientos y enseñanzas en diversos terrenos: el político, el literario, el económico, el social y, por supuesto, el histórico; en este sentido, el proyecto de Folletería Mexicana del Instituto Mora, pensado y diseñado para acercarnos a una importante fuente escrita, nos reveló muchas sorpresas. Una de ellas fue la enorme cantidad de folletos localizados en diversos archivos y bibliotecas nacio- nales y extranjeros. Otra, Ja variedad de temas abordados en este instrumento de difusión, tan importante como la prensa, ya que sirvió para complementar la información que los diarios - por diversas razones- no alcanzaban a cubrir. Acaso uno de los puntos más relevantes de este acercamiento a la folletería haya sido el descubrir que nos permite la aproximación a un tema o a una región de manera muy puntual, así como el análisis de temas muy generales y periodos muy extensos.

Si bien es cierto que este trabajo conlleva ciertas limitaciones porque 
refleja solamente el contenido de ciertos fondos y no toda la producción escrita de la época en cuanto a folletos, sí muestra -de manera aproximativa-qué temas interesaban, a quiénes iban dirigidos, quiénes los editaban, en qué lugar y cómo eran utilizados para entablar diálogos, sobre todo en relación con temas políticos. El folleto permitió abordar de modo preciso temas relacionados con la Iglesia, con los descubrimientos científicos, las artes, la educación, la economía, la historia y la legislación, entre otros.

Entre esa multiplicidad de materias, una en particular llamó mi aten. ción: la organización de la justicia. Un pequeño apartado de la categoría que se clasificó como Obra jurídica, dentro de ese vasto universo de la folletería. En este rubro los escritos fueron agrupados, por su contenido, en alegatos, amparos, circulares, códigos, constituciones, dictamenes, discursos, estatutos, fallos, leyes, ordenanzas, polémicas, proyectos de ley, puntos de derecho, testamentos y, por supuesto, organización de la justicia.

Una aproximación cuantitativa de estos escritos nos proporciona datos interesantes; por ejemplo, el mayor número de ellos lo constituye el apartado de leyes durante el periodo que va de 1821 a 1857 , pero destaca que, entre los años de 1821 a 1836 , la producción de decretos parece incrementarse; esto parece congruente si consideramos que, durante este periodo, los gobernantes se empeñaron en crear un cuerpo legislativo que reemplazara al utilizado durante los años de la colonia y que, por cierto, siguió vigente hasta muy avanzado el siglo XIX.
Durante esos primeros años del México independiente, la administración de la justicia ocupó un lugar primordial en la atención del gobierno, ya que resultaba importante coordinar diversos aspectos relacionados con la marcha de la nación, como legislar, entre otras cosas, para castigar a los delincuentes; reglamentar, ordenar y expeditar los trámites relacionados con la seguridad pública; agilizar el trabajo de los tribunales y juzgados, entre otros muchos asuntos preocupantes; esta tarea derivó en la producción de una enorme cantidad de proyectos de ley, dictámenes, reglamentos, circulares, exposiciones y decretos que reflejan de manera aproximativa la enorme responsabilidad que representó para los gobernantes conformar el Estado mexicano.

\section{LAS PISTAS}

Pero, ¿qué nos dicen los folletos? En un primer acercamiento a la categoría en donde se agruparon escritos jurídicos, los temas resultan por demás variados. Así, encontramos circulares que regulan el uso del papel común en las presentaciones judiciales -lo cual podría parecernos bastante trivial-, y otras en donde se confirman todos los tribunales, justicias y autoridades civiles y militares que desempeñaban actividades en el sistema colonial para continuar con sus funciones en la administración del país ahora independiente -asunto de vital importancia-; ello en un afán muy válido de no entorpecer la marcha de la administración de justicia. Sin embargo, conforme los 
años fueron transcurriendo pudo advertirse que el hecho de validar a las autoridades y continuar aplicando el corpus legislativo colonial no había resultado la mejor opción porque, sin preverlo, se crearon embrollos y vicios, pues a lo ya existente se sumaron nuevas disposiciones; así, la aplicación por ejemplo de las Siete Partidas, los Autos Acordados y las Leyes de Recopilación, resultaron cada vez más ajenos a la realidad del México independiente. Esto, sumado a la carencia de elementos humanos capaces, que tuvieran conocimientos apropiados para entender, interpretary aplicar las leyes -antiguas y nuevas-, fueron creando un clima de ineficiencia administrativa que dificilmente podría ser solucionada durante la primera mitad del siglo XIX.

Si a ello agregamos que no se contaba con el número suficiente de jueces letrados que atendieran la enorme demanda de aprehensiones, juicios, apelaciones, indultos y castigos para los miembros de una sociedad por demás desigual, que favorecía sólo a unos cuantos y que condenaba a la mayoría a la desesperación, al hambre y a la miseria orillándolos a la delincuencia, podríamos entender que el intento por lograr una continuidad en el proceso administrativo judicial derivó, con el paso del tiempo, en un embrollo cada vez más complicado al superponer y complementar leyes antiguas con las nuevas, de tal manera que, para 1822 , ya había quien se lamentaba sobre la "ejecución de la justicia" en un folleto así titulado y, en el mismo año, el Ministerio Fiscal denunciaba, en otro escrito a la Audien- cia, las causas que estaban influyendo en la frecuencia de robos, homicidios y demás delitos.

Y es que las condiciones económicas, políticas y sociales del nuevo país poco a poco se diferenciaban y modificaban en comparación con las que habían predominado hasta finalizar el siglo XVIII y, sin embargo, se continuaban aplicando las mismas leyes y procedimientos judiciales de entonces. Algunos decretos de 1824 dejan entrever la preocupación existente, por ejemplo, para delimitar y regular funciones al establecer el Supremo Tribunal de Justicia, o determinar sobre los sueldos correspondientes al fiscal y ministros de la Suprema Corte de Justicia, o el que, derivado del Congreso general, señalaba los procesos de elección, así como el periodo de funciones y actividades del presidente cle ese organismo.

Esta inquietud también se manifestó en el interés por actualizar algunos manuales a la modernidad decimonónica. Así nos lo revela el Apéndice que se hace al Manual de práctica forense de Eugenio Tapia, con "anotaciones dirigidas a acomodar las doctrinas de dicha obra a nuestra actual legislación", publicado en 1830. Llama la atención que cuatro años después se haya publicado un Plan para el mejor arreglo de la administración de justicia de Texas, cuando dicho territorio estaba ya en serios problemas debido precisamente a la falta cle ese elemento, y no muy lejos del momento de declarar su separación del territorio nacional.

Como ya hemos apuntado, uno de los problemas que en mayor grado 
afectó al ramo administrativo, fue la falta de abogados en el país, ya que era un hecho que la justicia estaba en manos de alcaldes y jueces iletrados que intentaban aplicarla, y que en ese intento la desviaban o la embrollaban aún más. Consecuencia de ello resultó que muchas causas criminales no se concluyeran en los periodos marcados por la ley, debido fundamentalmente a la carencia de algunos elementos necesarios para dictar sentencia y que, por obligación, debía incluir el alcalde al iniciar la sumaria del caso. Este hecho, demasiado frecuente y en la práctica diseminado a lo largo y ancho del territorio nacional, vino a repercutir directamente en el trabajo que desempeñaban los abogados, que eran quienes se veían abrumados al tratar de resolver las causas de segunda o tercera instancia que llegaban a sus manos sin los datos suficientes para hacerlo de manera expedita.

Así, quienes resultaban acusados de ineptitud eran aquellos a los que les tocaba examinar el proceso final, los jueces letrados. Muchos de ellos protestaron y con razón, ya que además de trabajar en forma desmedida debido al retraso de los expedientes acumulados, no recibían su salario oportunamente, situación que los obligaba a vivir en casos de extrema miseria y buscar en otros medios el ingreso compensatorio para alimentar a sus familias. Sus demandas también aparecieron reflejadas en los folletos. Por ejemplo, Juan Rodríguez de San Miguel publicó en 1835 la Vindicación de los que se dedican a la abogacía, muy probablemente en respuesta a los ataques que públicamente reci- bían por su "falta de luces y entendimiento" en relación con los problemas que aquejaban a la aplicación de la justicia por entonces y que ya mencionamos.

Al año siguiente, la Suprema Corte de Justicia hacía público un folleto en donde ese organismo -y los jueces de letras que lo integraban- exponían el estado de la administración de justicia en lo criminal y "las verdaderas causas del atraso que se advierte en la aprehensión y castigo de algunos delincuentes". Al parecer, las vindicaciones y exposiciones pronto tuvieron eco, pues al siguiente año, 1837, apareció publicada la Ley para el arreglo de la administración de justicia en los tribunales y juzgados del fuero común en por lo menos tres ediciones: una en Guadalajara, otra por el Ministerio de lo Interior y una más en la ciudad de México.

Sin embargo, y a pesar de que leyes y más leyes se promulgaban, todavía para el año de 1839 algunos lugares no contaban con un elemento de primordial importancia en cuanto al tema que venimos tratando: los juzgados de primera instancia, primera fase del proceso en cualquier causa criminal o civil que se iniciara. Y si bien ya se había decretado la norma sobre arreglo de administración de justicia mencionada unas líneas antes, al parecer no se contaba con juzgados de este tipo y en número suficiente, según lo manifestó José Manuel Sozaya en una apelación dirigida al "tribunal de la opinión pública" respecto de la injusta omisión ejercida por la Junta Departamental de México en este sentido, que privaba de ese elemento primordial 


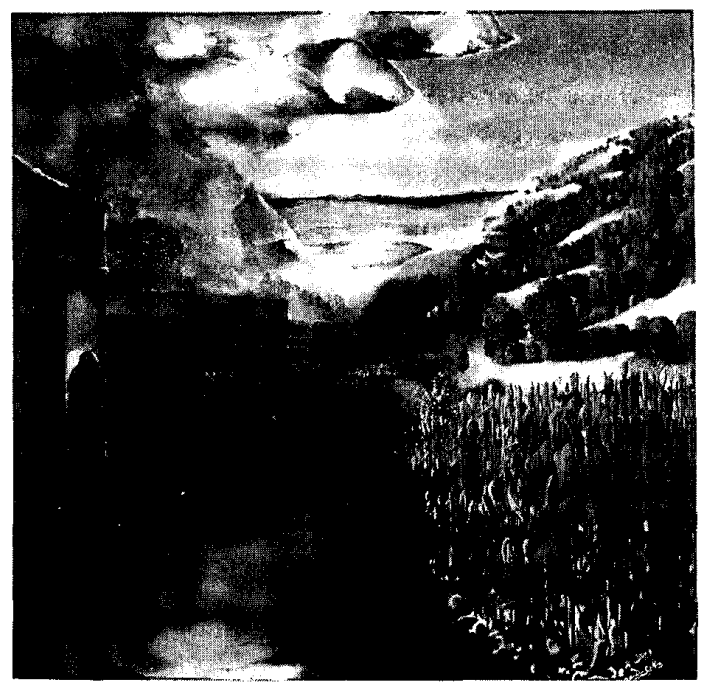

para que la justicia, en verdad pudiera ser administrada de manera eficientey expedita.

Enormes resultaron las dificultades para la pronta organización de la justicia en México: recursos económicos insuficientes, carencia de elementos humanos preparados y falta de juzgados de primera instancia; a ello debía agregarse que, en muchos lugares, las distancias que separaban a una población de otra eran considerables, y que las vías de comunicación se encontraban en pésimas condiciones. Todos estos factores incidían de manera determinante no sólo en la aplicación de la justicia, sino en los diversos elementos que regulaban la marcha del recién establecido Estado mexicano.

Lo impracticable de algunos pre- ceptos legales debido a las condiciones ya mencionadas, aunado a los cam. bios de sistema-de federal a central y viceversa-, derivaron en situaciones como la siguiente: cuando apenas habían pasado seis años de la promulgación de la ley que arreglaba la administración de justicia en los tribunales y juzgados del fuero común, se decretó otra destinada al mismo fin, de tal manera que ambas continuaron vigentes, por lo menos en algunos puntos, como el que se señaló en otro folleto que a la letra dice: Los jueces de letras del Distrito Federal continuarán actuando cinco en el ramo civily cinco en el criminal, según lo dispone la ley de 23 de marzo de 1837, publicado en 1846. A esto nos referimos cuando hablamos de "embrollo legislativo", 
ya que resulta muy probable que este tipo de disposiciones entorpeciera la marcha de la justicia en lugar de favorecerla. Esto se vería reflejado años más tarde, en 1852, cuando se promovieron nuevamente proyectos de decretos encaminados a "organizar la administración de justicia" que derivarían en una nueva Ley para el arreglo de la administración de la justicia en los tribunales y juzgados del fue ro común, publicada en 1853 y que antecedería a la de 1857 , expedida el 4 de mayo por Ignacio Comonfort casi con el mismo nombre.

\section{LOS NÚMEROS}

Dentro de la producción de folletería agrupada como Obra jurídica, destaca numéricamente -después del rubro denominado Leyes-el que agrupa alegatos, exposiciones, informes y querellas en donde se abordan asuntos sobre ilegalidades reportadas por la Suprema Corte de Justicia o alguna otra dependencia, causas de conspiración, defensas, conductas de funcionarios, documentos sobre acreedores, comentarios sobre juicios, asesinatos y muchos temas más. Siguiendo este orden numérico, resulta relevante la numerosa producción en cuanto a polémicas y proyectos de ley para los años que van de 1837 a 1851 y que aparecen minimizados para los periodos anterior y posterior a éste.

Un recuento de los folletos agrupados en el rubro de Organización de la justicia en el periodo que va de 1821 a 1857 dio como resultado la publicación de 148 impresos, de los cuales
44, o sea la mayor parte, se encuentran ubicados en la colección Lafragua de la UNAM, 39 en la biblioteca de Bancroft; los siguientes 37 se localizaron en el acervo de Condumex, doce más en el de Guadalajara; seis de ellos están depositados en la Universidad de Austin; cinco en el Instituto Mora; dos pertenecen a las colecciones de Yale y Sutro, y uno en cada una de las siguientes bibliotecas: Basave, Orozco y Berra y la Nacional de Antropología e Historia. Esto no quiere decir que los impresos se encuentren únicamente en los acervos mencionados, ya que algunos de ellos están salvaguardados en varios repositorios; sin embargo, para el conteo realizado se tomaron en cuenta, de manera primordial, los ubicados en archivos nacionales.

En consecuencia, podemos apreciar que gracias a la disciplina e interés de algunos hombres como José María Lafragua, disponemos en México de un enorme acervo bibliográfico en cuanto a folletería, y casi lo mismo podríamos decir si nos referimos a la labor que ha realizado el Centro de Estudios de Historia Condumex, agrupando una cantidad importante de dicha producción. Desafortunadamente, un número casi tan importante está en manos de bibliotecas extranjeras, por lo menos en lo que respecta al rubro de Justicia, ya que una porción considerable de estos folletos se encuentra ubicada solamente en el fondo Bancroft, razón suficiente para que la posibilidad de consulta por la mayoría de los historiadores mexicanos se considere muy lejana.

Por otra parte, resulta significativo que aun cuando un número conside- 
rable de cuadernos se encuentran al alcance del historiador en México, éste parece haberlos desdeñado en función de otras fuentes de igual importancia, hasta hace muy poco tiempo en que algunos investigadores han comenzado a leer e interesarse por lo que "dicen" los folletos. De ahí la importancia del trabajo realizado en proyectos como el de Folletería Mexicana del Instituto Mora, ya que permiten que este vasto y rico material generado durante el siglo XIX, se aprecie cada vez más en su justa medida como elemento que refleja el acontecer, sentir y pensar de los hombres que con sus luchas, enfrentamientos, discursos y acciones en el plano político, militar e intelectual, conformaron el Estado nacional, y que se intentan rescatar para todos aquellos interesados en seguir descubriendo, de manera diferente, la historia de nuestro país.

Al parecer, la línea en cuanto a editores e impresores de los folletos, estaba dirigida a que los imprimieran aquellos que aceptaran trabajar para el gobierno en calidad de contratistas, y muy pocos parecen ser, por lo menos para esta categoría, los que por cuenta propia imprimían cuadernillos encaminados a dirigir algún mensaje particular a la población interesada en asuntos de tipo político principalmente. Esto resulta lógico si consideramos que el rubro analizado se caracterizó significativamente por la publicición de documentos oficiales como decretos, memorias, circulares y proyectos. Por ello, dificilmente se registran folletos anónimos en este apartado.

Aun cuando la mayoría de los escritos, 77 de ellos, se refieren a la situación de México en general, les siguen, en cuanto a asuntos de los estados en particular; diezal Distrito Federal; ocho a Jalisco y Puebla; cinco a Sonora; cuatro a San Luis Potosí; dos a Veracruz, Nuevo León, Michoacán y Oaxaca, y un folleto para cada uno de los siguientes estados: Coahuila y Texas, Tamaulipas, Durango y Tabasco. Apoyándonos en estos datos, podríamos sugerir que la tarea encaminada a organizar la justicia estaba dirigida de manera primordial al Estado nacional, después a asuntos que atañían exclusivamente a la ciudad capital, y enseguida a los demás estados que conformaban al país. Ahora bien, aun cuando "no están todos los que son, ni son todos los que debieron publicarse", el recuento y observación de este periodo y de este rubro me han permitido bordar algunos señalamientos que sólo dejo así anotados. 


\section{SECUENCIA}

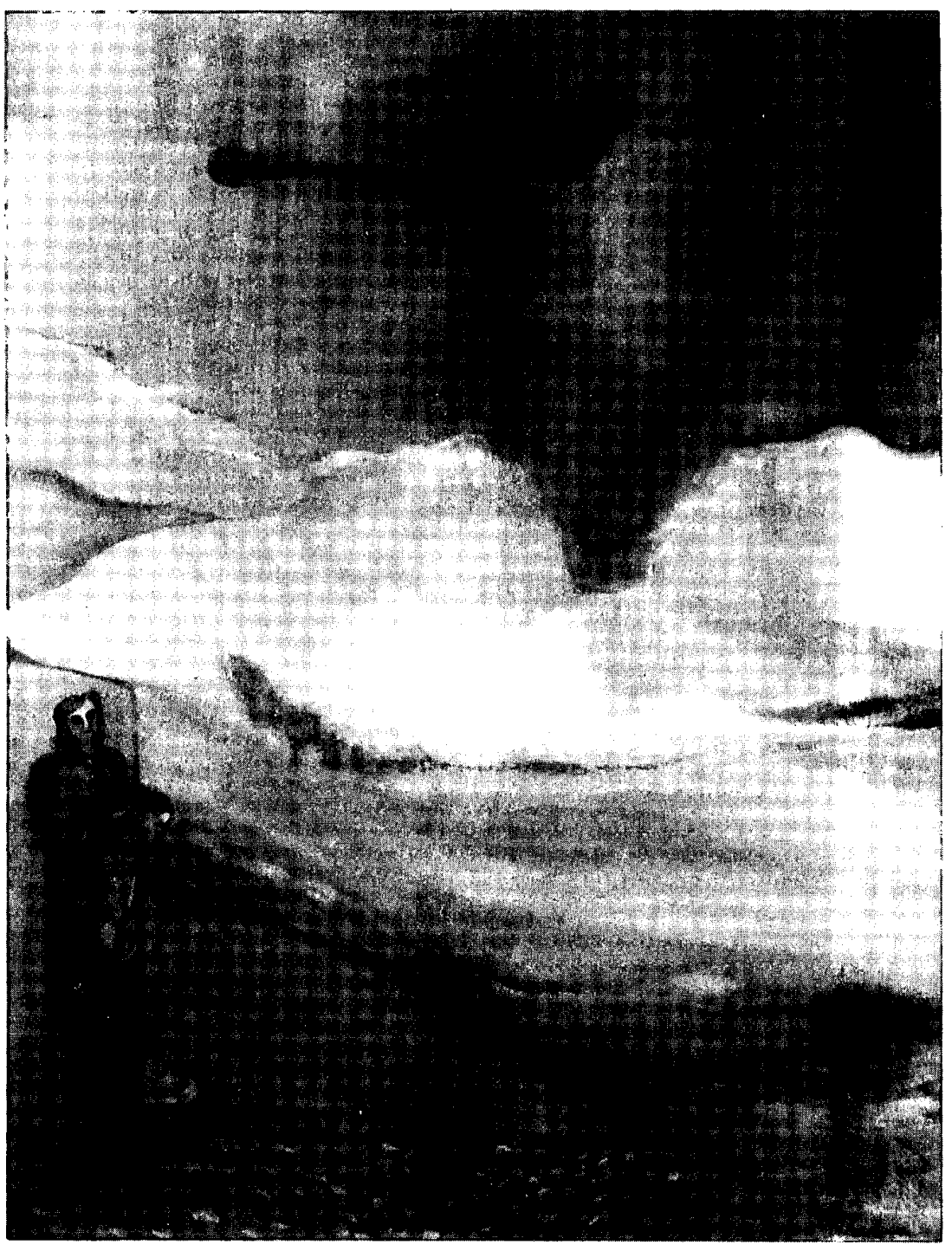

